\title{
Sensitized Near IR Luminescence of Er(III) Ion in Lanthanide Complexes Based on Diketone Derivatives: Synthesis and Photophysical Behaviors
}

\author{
Nam Seob Baek, Bong Kyu Kwak, Yong Hee Kim, and Hwan Kyu Kim ${ }^{\dagger * *}$ \\ Department of Athanced Materials, Hannam Lniversity, Daejeon 306-791, Korea. "E-mail josephinamail hantmack \\ ${ }^{\dagger}$ Deparment of Chemistry, Korea University, Jochion, Chungnam 339-700, Korea. "E-mail: hkk777akorea ac.kr \\ Received April 19, 2007
}

\begin{abstract}
Two $\beta$-diketone derivatives bearing triphenylene (1-naphthalene-2-yl-3-triphenylen-2-yl-propane-1.3-dione (NTPD)) and naphthalene (1.3-di-naphthalene-2-yl-propane-1.3-dione (DNPD)) and their Ln(III) complexes $(\mathrm{Ln}=\mathrm{Er}$ or $\mathrm{Gd})$ were synthesized and their photophy sical properties were investigated. The sensitized emission of $\mathrm{Er}^{3+}$ ion in $\mathrm{Er}^{3+}$-[NTPD $]_{3}$ (terpy) and $\mathrm{Er}^{3-}$-[DNPD $]_{3}$ (terpy) was observed upon excitation at absorption maximum of ligands. Their photophysical studies indicate the sensitization of $\mathrm{Er}^{3+}$ luminescence by energy transfer through the excited triplet state of $\beta$-diketone ligand. The energy transfer rate through the excited triplet state of $\beta$-diketone ligand to $\mathrm{Er}^{3-}$ ion occurs faster than that of the oxygen quenching rate.
\end{abstract}

Key Words : Lanthanide(III)-cored complexes. Energy transfer pathway. Triplet state. Near infrared (NIR) emission

\section{Introduction}

The $4 f$ electrons in lanthanide $\left(\mathrm{Ln}^{3+}\right)$ ions are slightly perturbed by the effects of lattice phonons and static strain fields in the coordination environment of ions. since the $f$ electrons are shielded by the outer $5 s$ and $5 p$ electrons. It leads to the sharp spectral line-like emission bands which properties are applied to various research fields. Especially near infrared emission of lanthanide ion has drawn much attention in a wide variety of photonic applications such as planar waveguide amplifiers. plastic lasers. light-emitting diodes and luminescent probes ${ }^{1-6}$ However the $4 f^{n}-4 f^{n}$ absorption and emission cross section of lanthanide ion is too low. To overcome these shortcomings. luminescent organic ligands are introduced to complexes of these metals. ${ }^{7.8}$ The lanthanide ions in luminescent lanthanide complexes are sensitized by energy transfer from the organic ligand to lanthanide ion, resulting in high luminescent quantum yield of lanthanide ion.

Among the numerous organic ligands. $\beta$-diketone ligands were well-known as a sensitizer to be utilized for the development of luminescent lanthanide complexes with the visible $\mathrm{Ln}^{3+}$ emissions. such as $\mathrm{Eu}^{3-}, \mathrm{Tb}^{3-}$ and $\mathrm{Sm}^{3+}$ ions. Their sensitization process is that a central metal ion is excited through the excitation of the ligand and then the excited energy of the ligand is transferred to the central ions through the ligand's triplet energy level. ${ }^{\text {li-1: }}$ The energy transfer between the triphenylene functionalized antenna and metal ion takes place through the triplet state of triphenylene because of high interșystem crossing (ISC) efficiency of triphenylene. In this paper. we have synthesized $\operatorname{Er}(\mathrm{III})$-cored complexes based on triphenylene- and naphthalene-functionalized $\beta$-diketone and investigated the photophysical processes.

\section{Experimental}

\section{Synthesis and Analysis}

2-Acetyltriphenylene: To anhydrous solution of nitrobenzene $(10 \mathrm{~mL})$, triphenylene $(1.0 \mathrm{~g} .4 .38 \mathrm{mmol})$ and $\mathrm{AlCl}_{3}$ $(1.17 \mathrm{~g} .8 .76 \mathrm{mmol})$ and acetyl chloride under $\mathrm{N}_{2}$ were added. The mixture was stirred at $0^{\circ} \mathrm{C}$ for $2 \mathrm{~h}$ and cooling bath was removed and the reaction mixture was stirred at room temperature overnight. The mixture was poured into ice water. extracted with $\mathrm{CHCl}_{3}$. the organic layer was washed with water. and dried with anhydrous $\mathrm{MgSO}_{4}$. The crude mixture was finally purified by column chromatography ( $\mathrm{SiO}_{2}, \mathrm{CHCl}_{3}$ ). Yield: $99 \%$.

${ }^{l} \mathrm{H}-\mathrm{NMR}\left(\mathrm{CDCl}_{3} .300 \mathrm{MHz}\right)[\mathrm{ppm}]: \delta 9.19(\mathrm{~d} . \mathrm{lH}), 8.70-$ $8.58(\mathrm{~m} .5 \mathrm{H}) .8 .16(\mathrm{dd} .1 \mathrm{H}) .7 .70-7.64(\mathrm{~m} .4 \mathrm{H}) .2 .77(\mathrm{~s} .3 \mathrm{H})$ : ${ }^{13} \mathrm{C}-\mathrm{NMR}\left(\mathrm{CDCl}_{2} . \mathrm{ppm}\right): \delta$ 197.74, 134.98, 133.13. 130.54 . $129.76,129.33,128.72$. 128.24, 127.66, 127.42, 127.31. 126.06. 123.88. 123.47. 123.27, 123.22, 26.91.

1,3-Di-naphthalen-2-yl-propane-1,3-dione (DNPD): A solution of 2-acetonaphthalene $(2.0 \mathrm{~g}$. $11.75 \mathrm{mmol})$ and methyl 2-naphthalenoate (2.63 g. $14.10 \mathrm{mmol})$ in dry THF $\left(70 \mathrm{~mL}\right.$ ) was purged with $\mathrm{N}_{2}$ for $10 \mathrm{~min}$. The sodium ethoxide (0.96 g. $14.10 \mathrm{~mm}$ ol) was added and the mixture was stirred for 24 hrs at $60^{\circ} \mathrm{C}$. After cooling down. hydrochloric acid was added and the organic layer exhaustively extracted with chloroform. The combined organic layers were washed with a saturated solution of $\mathrm{NaHCO}_{3}$. then with water. dried $\left(\mathrm{Na}_{2} \mathrm{SO}_{4}\right)$ and concentrated under reduced pressure. The crude mixture was finally purified by column chromatography $\left(\mathrm{SiO}_{2}, \mathrm{CHCl}_{3}\right)$. Yield: $66 \%$.

${ }^{l} \mathrm{H}-\mathrm{NMR}\left(\mathrm{CDCl}_{3 .} .300 \mathrm{MHz}\right)[\mathrm{ppm}]: \delta 8.59$ (d. $\left.2 \mathrm{H}\right) .8 .08-$ 7.89 (m. 8H). $7.62-7.43$ (m. 4 H). 7.15 (s. 1H): EI-MS: $m z$ calcd for $\mathrm{C}_{33} \mathrm{H}_{16} \mathrm{O}_{2} 324.37$. found $\left[\mathrm{M}^{-}\right] 324$.

1-Naphthalen-2-yl-3-triphenylen-2-yl-propane-1,3-dione 
<smiles>CC(=O)c1ccc2c3ccccc3c3ccccc3c2c1</smiles><smiles>CCON=C(C(=O)OCC)[C@H](C(=O)OCC)c1ccc2ccc(C(=O)CC(=O)c3ccc4ccccc4c3)cc2c1</smiles><smiles>CCON=C([C@H](C)OC(C)=O)C(F)(F)F</smiles>

Scheme 1<smiles>[R]C(=O)CC(=O)c1ccc2ccccc2c1</smiles>

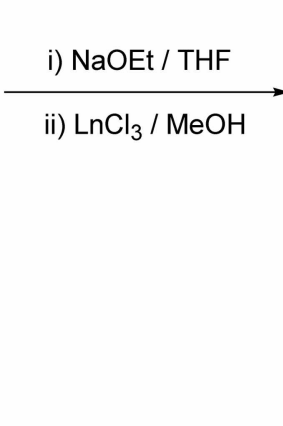

Scheme 2
(NTPD): Synthesis of NTPD was carried out in a similar manner to that of DNPD. Yield: $65 \%$.

'H-NMR (CDCl, $300 \mathrm{MHz}$ ) [ppm]: $\delta 9.34(\mathrm{~d}, \mathrm{IH}), 8.82$ (m, lH), 8.75 (d, IH). 8.70-8.63 (m, 4H), 8.26 (dd, IH), 8.12-7.92 (m, 4H), 7.75-7.70 (m, 4H), 7.63-7.59 (m, 2H), $7.31(\mathrm{~s}, 1 \mathrm{H})$; EI-MS: $m / z$ calcd for $\mathrm{C}_{31} \mathrm{H}_{20} \mathrm{O}_{2} 424.15$, found $\left[\mathrm{M}^{+}\right] 424$.

Synthesis of $\mathrm{Ln}^{3+}$-|diketone| ${ }_{3}($ terpy): General Procedure. ${ }^{50} \mathrm{~A}$ mixture of appropriate diketone ligand (3 equiv.) and $\mathrm{NaOEt}$ ( 3.3 equiv.) was stirred in freshly distilled $\mathrm{IHH}$ at room temperature for $1 \mathrm{~h}$. After the formation of salts was completed, the methanol solution of anhydrous $\mathrm{LnCl}_{3}$ (I equiv.) ( $\mathrm{Ln}=\mathrm{Er}$, or $\mathrm{Gd}$ ) and $2,2^{\prime}: 6^{\prime} 2^{\prime \prime}$-terpyridine ( 1.1 equiv.) was added to the reaction solution, and then stirred for 48 hrs. The resulting solution was filtered and the solvents were removed. The resultant solid was washed sequentially with methanol, hexane and diethyl ether, yielding a yellowish solid.

$\mathbf{E r}^{3+}-|\mathbf{D N P D}|_{3}($ terpy): Yield: 51\%. Anal. Caled for $\mathrm{C}_{84} \mathrm{H}_{66} \mathrm{~N}_{3} \mathrm{O}_{6} \mathrm{Er}: \mathrm{C} .73 .61 ; \mathrm{H}, 4.12 ; \mathrm{N}, 3.07 ; \mathrm{Er}, 12.20$; found: C. $72.23 ; \mathrm{H}, 4.57 ;$ N. $2.78 ; \mathrm{Er}, 12.69$.

Gd $^{3+}-$ |DNPD $\left.\right|_{3}$ (terpy): Yield: $66 \%$. Anal. Calcd for $\mathrm{C}_{84} \mathrm{H}_{56}, \mathrm{~N}_{3} \mathrm{O}_{6} \mathrm{Gd}: \mathrm{C} .74 .15 ; \mathrm{H}, 4.15 ; \mathrm{N}, 3.09$; found: $\mathrm{C} .73 .35$;
H. 4.73; N. 2.82 .

$\mathbf{E r}^{3+}-$ INTPD| $_{3}($ terpy $):$ Yield: $72 \%$. Anal. Calcd for $\mathrm{C}_{1(18} \mathrm{H}_{68} \mathrm{~N}_{3} \mathrm{O}_{6} \mathrm{Er}: \mathrm{C}, 77.63 ; \mathrm{H}, 4.10 ;$ N. 2.51; $\mathrm{Er}, 10.01$; found: C. 76.86; H. 4.37; N, 2.36; Er, 10.32 .

$\mathrm{Gd}^{3+}-\left[\left.\mathbf{N T P D}\right|_{3}\right.$ (terpy): Yield: $46 \%$. Anal. Calcd for $\mathrm{C}_{1188} \mathrm{H}_{48} \mathrm{~N}_{3} \mathrm{O}_{6} \mathrm{Gd}: \mathrm{C}, 78.10 ; \mathrm{H}, 4.13 ; \mathrm{N}, 2.53$; found: C. 76.98; $\mathrm{H}, 4.63 ; \mathrm{N}, 2.42$.

Spectroscopic measurements. All solvents for the optical measurements were the spectroscopic grade and used without further purification. Steady-state UV-vis absorption spectra were recorded with a Shimadzu UV-240IPC spectrophotometer at room temperature. The fluorescence emission and excitation spectra were measured using an Edinburgh $\mathrm{FS} 920$ fluorometer with $450 \mathrm{~W}$ Xe-lamp. Visible emission spectra were taken with a PMI system (Hamamatsu R955) and near-infrared emission spectra were taken with Ge-detector (Edinburgh El-L) cooled by the liquid nitrogen. To measure low-temperature luminescence. the samples were degassed by argon bubbling for $30 \mathrm{~min}$. and measured by using optical dewar. Fluorescence quantum yields $\left(\phi_{1}\right)$ of ligand and complexes were estimated using a 9.10-diphenylanthracene as a standard with a known value of $\phi_{\mathrm{f}}=0.9 .^{1 . \overline{\mathrm{r}}}$ 
The microsecond time-resolved emission measurements were carried out by using a Nd:YAG laser. The third harmonic generation $(355 \mathrm{~nm}, 5 \mathrm{~ns}$ pulse width at $10 \mathrm{~Hz}$ repetition rate) of Nd:YAG laser (EXSPLA N'l'342) system was used to excite the ligand moiety. The emission spectrum was analyzed with a monochromator (Acton spectrapro 2300i) and detected with a photomultiplier followed by a digital oscilloscope (Agilent infiniium 54832B DSO).

\section{Results and Discussion}

We have developed lanthanide( III) ( $\mathrm{Ln}(\mathrm{III})$ or $\mathrm{Ln}^{3+}$-cored complexes based on 1,3-di-naphthalene-2-yl-propane-1,3dione (DNPD) and 1-naphthalene-2-yl-3-triphenylen-2-ylpropane-I,3-dione (NTIPD) for near IR emission to investigate the energy transfer pathway from the antenna ligand to the $\mathrm{Ln}^{3-}$ ion. I $\mathrm{n}(\mathrm{III})$ complexes were prepared by ligandexchange reaction using anhydrous $\mathrm{LnCl} l_{3}$, as illustrated in


Figure 1. UV-vis absorption spectra of (a) NIPD) and L L $7^{31}$ [.TPD] $]_{\text {(terpy) (b) D } \backslash P D}$ and $\mathrm{Ln}^{3}{ }^{3}-[\mathrm{DNPD}]_{3}$ (terpy) at $298 \mathrm{~K}$ in THF $\left(\lambda_{\mathrm{es}}=375 \mathrm{~nm}\right.$. Conc. $\left.=2.0 \times 10^{-5} \mathrm{M}\right)$.
Scheme 2. The highly-coordinated complexation of the $\mathrm{Ln}^{3+}$ ion with NTPI) or DNPD as well as one terpyridine (terpy) was formed. $\mathrm{Ln}^{3+}$ jons were effectively encapsulated by a $\beta$-diketone derivatives and terpyridine. The chemical structures of all materials were identified by $\mathrm{F}[-\mathrm{IR}$. ' $\mathrm{H}$ - and F.I-mass, FA, UV-vis absorption and emission spectroscopic methods.

Figure 1 shows the UV-vis absorption spectra of NTPD. DNPD and their $\mathrm{Ln}(\mathrm{III})$ complexes. NTPD and DNPD exhibit the absorption bands in the spectral regions of 250-300 $\mathrm{nm}$, which are attributable to triphenylene and naphthalene, in addition to the broad and structureless absorption band centered at around $360-400 \mathrm{nIn}$ are assigned to spin-allowed $\pi-\pi^{*}$ transitions. Such absorptions spectra of NTP'] and DNPI have been previously identified in the other $\beta$-diketone derivatives. ${ }^{14}$ Absorption spectra of ligands and complexes show very similar spectral features, indicating that the lanthanide ion does not significantly influence
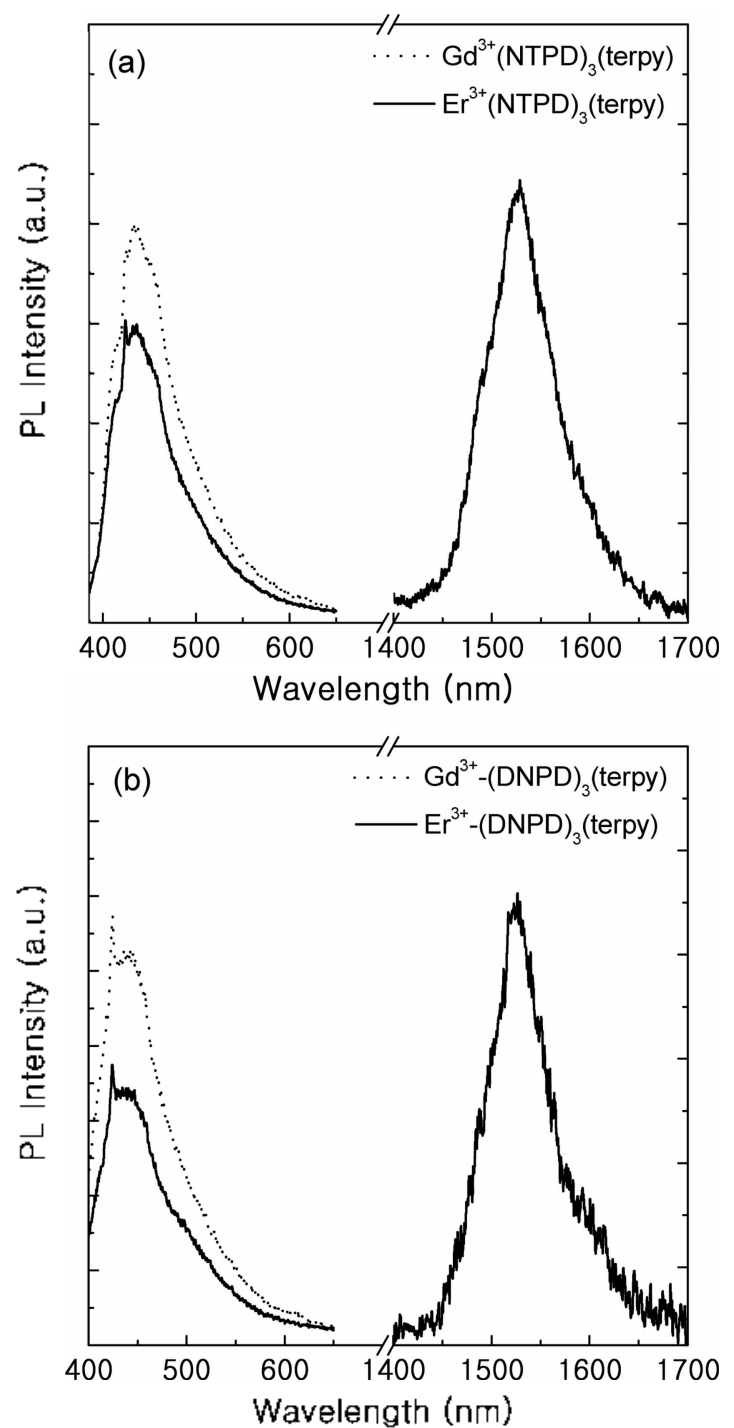

Figure 2. PL spectrat of (a) $\mathrm{Ln}^{\mathrm{i}-}-[\mathrm{NTPD}]_{3}(\mathrm{terpy})$ (b) $\mathrm{Ln}^{\mathrm{i}-}$ $[D . P D]_{i}($ terpy $)$ at $298 \mathrm{~K}$ in THF $\left(\dot{\lambda}_{\mathrm{es}}=375 \mathrm{~nm}\right.$. Conc. $=2.0 \times 10^{-5}$ M). 
the energy state of the NTPD or DNPD.

The PL spectra of NTPD, DNPD and their Ln(III) complexes with an excitation at $375 \mathrm{~nm}$ under same experimental conditions were obtained (Figure 2). The fluorescence spectra of the free ligands. NTPD and DNPD in mTHF showed very weak emission band. The fluorescence quantum yield of free ligands in Ln(III)-cored complexes is slightly decreased. compared with those of the free NTPD and DNPD ligand, although the intensity decrement is very small. This fact that the fluorescence quantum yield of the N'TPD and DNPD ligands is very low may be due to the higher ISC efficiency of ligands, resulting in enhancing the formation of the excited triplet state of the ligands. The decreased fluorescence quantum yield in the $\mathrm{Ln}$ (III) complexes is attributed to the fact that the intersystem crossing quantum yield is increased by heavy atom effect. In addition. sensitized emission spectra of $\mathrm{Er}^{3+}$ ion in the complexes


Figure 3. PL spectra of (a) Ln $\mathrm{Ln}^{31}-[\mathrm{NTPD}]_{3}$ (terpy) (b) $\mathrm{Ln}^{31}-$ [D.PD]; (terpy) at $77 \mathrm{~K} \mathrm{in} \mathrm{m-THF}\left(\lambda_{\mathrm{ex}}=375 \mathrm{~nm}\right.$. Conc. $=2.0 \times 10^{\circ}$ M). were observed at $1530 \mathrm{~nm}$, originated from $4 f-4 f$ electronic transition of the first excited state $\left(\mathrm{I}_{1-2}\right)$ to the ground state $\left({ }^{\prime} l_{15: 2}\right)$ of the partially filled $4 f$ shell.

The excitation spectrum of the $\mathrm{Er}^{3+}$-cored complex, monitored at the emission wavelength of $1530 \mathrm{~nm}$ which arises from the electronic transition of ${ }^{1} \mathrm{I}_{132} \rightarrow{ }^{4} \mathrm{I}_{192}$ of $\mathrm{Fr}^{3-}$ ion, closely matched the absorption spectrum of the corresponding ligand in the complex. It indicates that, upon the photoexcitation of the ligands, the excitation energy was mainly absorbed by the N'TPD and DNI'D ligands, and then transferred to the $\mathrm{Er}^{3+}$ ion. Generally, it is accepted that the emission spectra and decay time measurements for the Gd(II])-cored complexes allow the identification of the lowest triplet state of a ligand, which is generated by ISC process from the excited singlet state, because $\mathrm{Gid}^{3+}$ ion has a heavy atom effect and no energy level below $32.000 \mathrm{~cm}{ }^{1}$. As shown in Figure 3 , in the case of $\mathrm{Gd}^{3+}-[\mathrm{NTPD}]_{3}$ (terpy) and $\mathrm{Gd}^{3+}-[D N P D]_{\mathrm{s}}($ terpy), the luminescence spectra of $\mathrm{Gd}^{3-}$-complexes in $\mathrm{m}-\mathrm{THF}$ at $77 \mathrm{~K}$ exhibit a strong phosphorescence band with the fluorescence band of the corresponding ligands.

The lowest triplet state of NTPD and DNPD was determined from the 0 -0 transition in phosphorescence spectra. which values are about $19300 \mathrm{~cm}{ }^{3}$ in both of them. On the other hand, no phosphorescence was observed in both $\mathrm{Er}^{3-}$ $\left[\mathrm{N}[]^{2} D\right]_{3}\left(\right.$ terpy) and $\mathrm{C:}^{3-}{ }^{3-}[\mathrm{DNPD}]_{3}$ (terpy) upon photoexcitation at $375 \mathrm{~nm}$, implying that efficient energy transfer between the ligands and $\mathrm{Er}^{3-}$ ion takes place. As a result, the strong quenching of phosphorescence led us to postulate that excitation energy of the triplet excited state was transferred to the resonance levels of $\mathrm{Er}^{3-}$ ion.

lo obtain further information on the energy transfer process, we measured the phosphorescence decay profiles of $\mathrm{Ln}^{3+}-[\mathrm{NTPD}]_{3}$ (terpy) and $\mathrm{l}_{\mathrm{n}} \mathrm{n}^{3-}$-[DNPD] (terpy) with an excitation at $355 \mathrm{~nm}$. The decay profiles were monitored at $520 \mathrm{~nm}$ which corresponds to the emission of triplet state. The phosphorescence lifetimes of $\mathrm{Gd}^{3+}-[\mathrm{NTPD}]_{3}$ (terpy) and


respectively. However, the decay times of $\mathrm{Er}^{3-}-\left[\mathrm{N}[\mathrm{PD}]_{\mathrm{s}^{-}}\right.$ (terpy) and $\left.\mathrm{Er}^{3+}-[\mathrm{DNN}]^{3}\right]_{3}$ (terpy) are too short to be analyzed. It is probably due to the fact that the excitation energy of triplet state in $\mathrm{Er}^{3+}-\left[\mathrm{N}^{\prime} \mathrm{PPD}^{\mathrm{S}} \text { (terpy) }_{\text {and }} \mathrm{Er}^{3+} \text {-[DNPD }\right]_{3^{-}}$ (terpy) is transferred to $\mathrm{Er}^{3+}$ ion very quickly. Considering the spectral tendency of phosphorescence and decay time of triplet state in Ln(III)-cored complexes with N'TPD and DNPD, we can suggest that the energy transfer in $\mathrm{Er}^{3-}$ $[\mathrm{NIPD}]_{3}$ (terpy) and $\left.\mathrm{Er}^{3+}-\left[\mathrm{N}^{\prime}\right]^{\prime} \mathrm{D}\right]_{3}$ (terpy) takes place through the triplet state. It is in a good agreement with the interpretation, from the spectral dependency of the phosphorescence on oxygen concentration, that the strong sensitized $\mathrm{Er}^{3-}$ emissions in $\mathrm{Er}^{3+}-\left[\mathrm{N}^{\mathrm{T}} \mathrm{T}^{\mathrm{P}} \mathrm{D}\right]_{3}$ (terpy) and $\mathrm{Er}^{3-}$ $[\mathrm{DNP}]_{3}$ (terpy) are observed in both aerated and deoxygenated $\mathrm{THF}$ solution, upon the photoexcitation of the ligand at $375 \mathrm{~mm}$. On the basis of the results mentioned above, the energy transfer in $\mathrm{Er}^{3+}-\left[\mathrm{N}[\mathrm{PD}]_{3}\right.$ (terpy) and $\mathrm{Er}^{3-}$ $[\mathrm{DNPD}]_{3}$ (terpy) takes place through the triplet state and the energy transfer rate between the ligands and $\mathrm{Er}^{3-}$ has the 
larger order of magnitude than the oxygen quenching rate $\left(k_{\text {et }}>10^{7} \mathrm{~s}^{-1}\right)$.

\section{Conclusions}

We have developed the Er(III)-cored complexes based on NTPD and DNPD for near IR enission and investigated their energy transfer pathway using the steady state and time resolved spectroscopic measurement. Our experimental observations suggest that the $\mathrm{Ln}$ (III)-cored complexes based on NTPD and DNPD are effectively formed to be the triplet state by intersystem crossing process. The sensitization of $\mathrm{Er}^{3+}$ luminescence takes place by the effective energy transfer between the $\beta$-diketone ligand and $\mathrm{Ln}^{3-}$ ion through the excited triplet state of $\beta$-diketone ligand.

Acknowledgements. This research work was funcially supported by the Korea Research Foundation (R03-2004$000-10017-0$ ).

\section{References}

1. Ding. L.: Fang. Y:: Jiang. L: Gao. L: Yin. X. Thin Solid Filmes $2005,478,318$

2. (a) Ren. H: Gao, F: Tong Z: Yan. Y. Chem. Plys. Lett 1999. 307. 55. (b) Rettig. W.: Chandross, E. A. J. Am. Chem. Soc. 1985. 107.5617 .

3. Hebbink. G. A.: Klink. S. I.: Grave. L.: Alink. P. G. B. O.: van Veggel. F. C. J. M. ChenPlnschem. 2002. 3. 1014.
4. Vicinelli. V:: Ceroni. P.: Maestri. M.: Balzani. V.: Gorka. M. Vogtle. F. J. Am. Chent Soc. 2012. 124.6461.

5. (a) Kim. H. K.: Roh. S.-G.: Hong. K.-S.: Ka. J.W.: Baek. N. S.: Oh. J. B.: Nah. M. K: Cha, Y. H. Ko, J. Hacromol Res. 2003. 11, 133. (b) Kim, H. K.: Oh, J. B.; Baek, N. S.: Roh. S.-G: Nah. M. K.: Kim, Y. H. Bull. Kor: Chem. Soc. 2005, 26. 201. (c) Baek. N. S.: Kim. Y. H.: Roh. S.-G.: Kwak. B. K.: Kim. H. K. Ad Fumct. Mat 2006. 16. 1873. (d) Oh. J. B.: Nah. M.-K.: Kiml. Y. H.: Kan1. M. S.: Ka. J.-W.: Kim. H. K. Adh: Finct. Mater 2007.17. 413.

6. (a) Parker. D. Coord Chem. Rev 2000. 205, 109. (b) Kim, Y. H: Baek. N. S.: Kim. H. K. ChemPlnsChem 2006. 7, 2. 13.

7. Kim. Y. H.: Baek. N. S.: Oh. J. B.: Nah. M. K.: Roh. S. G.: Song. B. J: Kim. H. K. Macronol. Res. 2007. 15. 272

8. Baek. N. S.: Kim. Y. H.: Kim. H. K. Bull. Kon Chent Soc. 2006. 27. 1729 .

9. Oude Wolbers. M. P. van Veggel. F. C. J. M.: Snellink-Ruel. B. H. M: Hofstraat. J. W.: Geurts. F. A. J.: Reinhoudt, D. N. $J$. Am Chent. Soc. 1997. 119. 138.

10. Dawsont. W. R.: Kropp. J. L.: Windsor. M. W. J. Chent. Phns. 1966. 5.2410

11. Klink. S. I.: Hebtink, G. A.: Grave, L.: Oude, P. G. B.: van Veggel. F. C. J. M.; Werts. M. H. V. J. Phos. Chom A 2002, 106. 3681.

12. (a) Baldo. M. A.; Thompson, M. E.: Forrest. S. R. Pure Appl. Chent 1999. 71. 2095. (b) de Sá. G. F.: Malta. O. L.: de Mello Donlegá. C.: Simas. A. M.: Longo. R. L.: Santa-Cruz. P. A.: da Silva Jr. E. F. Coord Chem. Rev 2000. 196. 165.

13. (a) Krasovitskii, B. M.; Bolotin. B. M. Organic Luminescent 1/aterials: VCH: Weinheim, Germany. 1988. (b) Lakowicz. J. R. Principles of Fluorescence Spectroscopy: 2nd Ed: Kluwer Academic Plenum: New York. 1999. (c) Eaton. D. F. Pure. Appl. Chent 1988. 60. 1107.

14. Strasser. A.: Vogler. A. J. Photochem. Photobiol. 2004. 165.115. 